\title{
FIELD EXPERIMENTS ON RESPONSES OF A FRESHWATER, BENTHIC MACROINVERTEBRATE COMMUNITY TO VERTEBRATE PREDATORS ${ }^{1}$
}

\author{
JAMES H. Thorp AND E. A. BergeY" \\ Savannah River Ecology Laboratory, Post Office Drawer E, Aiken, South Carolina 29801 USA
}

\begin{abstract}
We examined the seasonal importance of vertebrate predators in potentially regulating the abundance and diversity of the benthic macroinvertebrates in the littoral zone of a soft-bottom reservoir that receives thermal effluent from a nuclear production reactor. Thirty-six predator (fish and turtle) exclusion cages $\left(4 \mathrm{~m}^{2}\right)$ were placed in shallow water at six locations along a thermal gradient in Par Pond, a 1100-ha cooling reservoir on the Savannah River Plant near Aiken, South Carolina, USA. An additional 36 control plots (4 $\left.\mathrm{m}^{-2}\right)$ were also set up. Cages were in place during three, 3-mo test periods beginning in September 1977. Estimates of benthic density, taxon richness, and distribution within functional groups (defined by feeding mechanism) were calculated for each test period. Effects of temperature on predator-prey relationships were also determined.

Experimental results of this study suggest that vertebrate predation was not the fundamental parameter organizing the benthic macroinvertebrate community in the littoral zone of this reservoir. Neither taxon richness nor density of total macroinvertebrates was conclusively related to predator treatment. Relationships between predator treatment and community response (changes in density and taxon richness) were generally unaffected by either plot locality, temperature fluctuations from thermal effluent, or seasonal changes. When data from caged and control plots were pooled, however, both location and water temperature individually had direct impacts on the benthic community.

From our results and other field studies we hypothesize that individual species of "keystone" benthic predators (Paine 1969h) do not occur in the littoral zone of freshwater lentic environments with soft bottoms. This hypothesis is based on the following four arguments. First, environmental heterogeneity should reduce predator efficiency relative to that found in rocky intertidal systems where keystone predation may be present. Second, relative food web complexity should reduce the community importance of an individual predator species. Third, the apparent relatively greater resource partitioning of space and food in the freshwater littoral zone hinders monopolization of ratelimiting environmental resources by a single dominant prey species. Fourth, the effects of predation may not be extensive enough in time or area to provide sufficient resource space (and thus food) for exploitation by fugitive species. Possible regulation by a guild of predators and cases where the general hypothesis might be falsified are discussed.
\end{abstract}

Key words: benthic community; fish; foundation species; insects, invertebrates; keystone species; predation; reservoir; Sav'annah River Plant; South Carolina; thermal stress.

\section{INTRODUCTION}

Except for a few studies on freshwater benthos (Ball and Hayne 1952, Hayne and Ball 1956, Hall et al. 1970, Benke 1976, 1978, Peckarsky 1979), the vast majority of experimental studies on predator-prey relationships in aquatic benthic communities have focused on marine intertidal or subtidal environments (e.g., Paine 1966, Connell 1970, Dayton 1971, Menge 1976, Menge and Sutherland 1976, Sutherland and Karlson 1977). The relative simplicity of experimental manipulation (aside from problems associated with securing cages to wave-swept rocks) and ease of separation of resident organisms (most of which are adults, unlike those in freshwater benthos) into distinct species and trophic positions, may account for the early success in deciphering patterns in predator-prey relationships among rocky intertidal and subtidal communities. Similar ex-

\footnotetext{
1 Manuscript received 7 January 1980; revised 15 May 1980; accepted 27 May 1980.

- Present address: Department of Zoology, Colorado State University, Fort Collins, Colorado 80521 USA.
}

perimental techniques were applied in estuarine softbottom communities with only moderate success (Woodin 1974, 1978, Virnstein 1977, 1979) as a result of difficulties in excluding known, epibenthic predators such as the blue crab, Callinectes sapidus (J. H. Thorp, personal observation, Virnstein 1979), and as a result of problems in excluding or manipulating infaunal predators, such as polychaetes and nemerteans. For historical and environmental reasons, progress in understanding benthic community regulation in freshwater environments has not, unfortunately, kept pace with advances made in marine and estuarine studies.

Paine $(1966,1969 a, b)$ coined the term "keystone species" to describe predators that disproportionately affect patterns of prey occurrence, distribution, and density. In his studies the se predators reduced or eliminated exploitation competition for primary space by selectively consuming prey (mussels) that were capable of monopolizing much of the primary space in the rocky intertidal zones. Despite suggestions that blue crabs may act as keystone predators in soft-bottom estuarine systems (or "foundation species" of high trophic status, Virnstein 1977), or that bluegill sunfish 


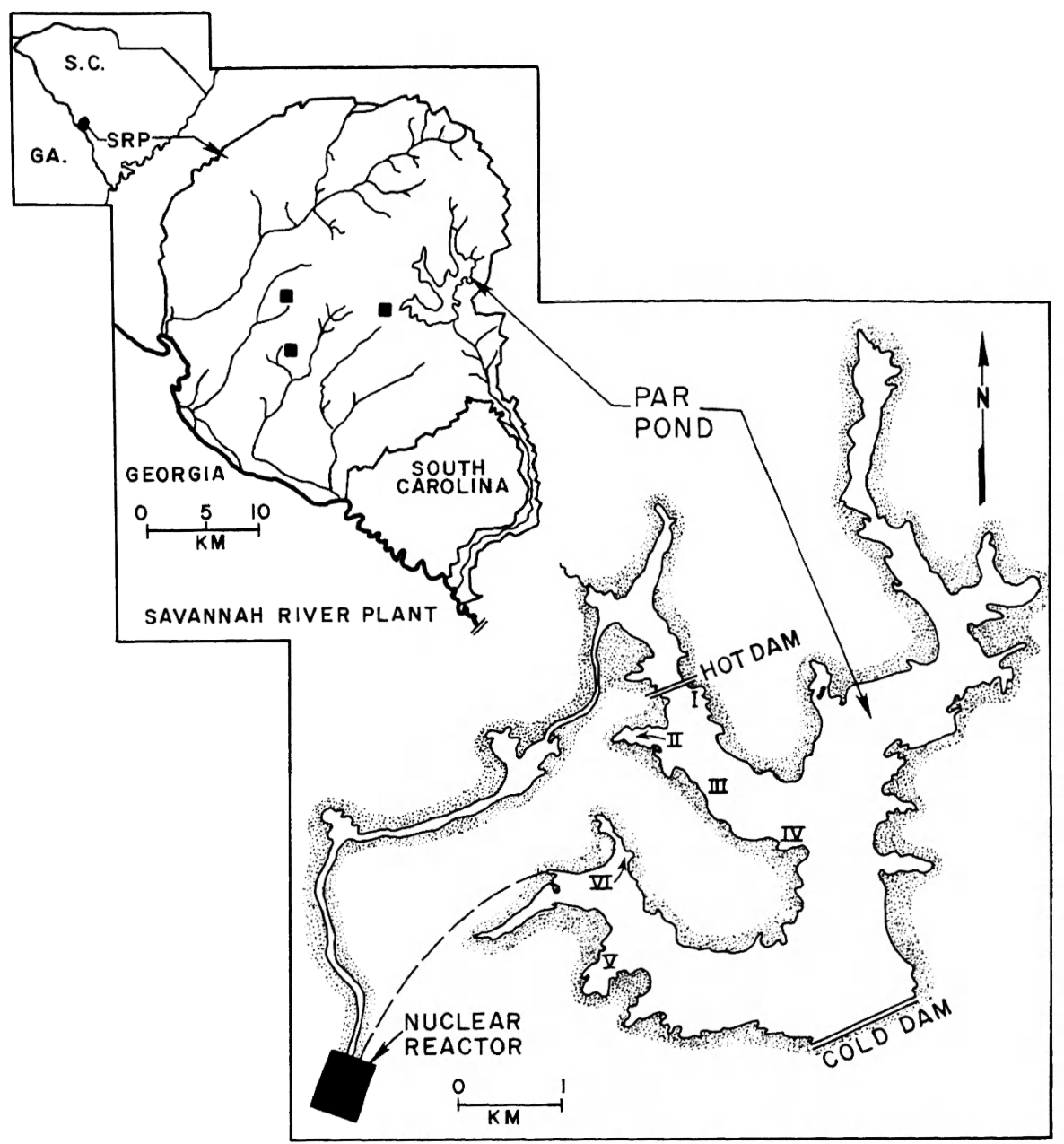

FIg. 1. Schematic drawing of the study area. Experimental areas are shown in Roman numerals. Stations I-IV receive thermal effluent but V and VI are in ambient temperature areas. Dark squares are active nuclear production reactors. Dashed line is the path of water pumped from Par Pond to cool the reactor.

(Lepomis macrochirus) may partially function in that role for benthos in freshwater ponds (Hall et al. 1970), no definitive evidence, in our opinion, has shown the existence of a keystone predator that feeds on benthos in freshwater or marine environments other than those in rocky intertidal or subtidal zones.

The primary purpose of our study was to determine whether vertebrate predation from either a keystone species or a guild was important in regulating the structure of the benthic macroinvertebrate community in the littoral zone of a freshwater reservoir. Technical difficulties resulting from high mortality of enclosed fish (possibly associated with a large bacterial population of infectious Aeromonas in our study area during the experiments) prevented us from directly testing for an individual species of keystone predator. However, lack of any appreciable effect from the guild of vertebrate predators in the reservoir would, in our opinion, indicate the absence of a keystone predator. Because keystone species have been found in hardbottom intertidal communities, we have contrasted biotic and abiotic characteristics in marine and freshwater environments in order to distingish those factors affecting the importance of predation in regulating the respective communities. We recognize that predation is not equally important for regulation in all rocky intertidal communities. We have focused our discussion on the effects of vertebrate predation on the total macroinvertebrate community and we will report elsewhere in detail the effects of this predation on the midge subcommunity (Diptera:Chironomidae). Experimental studies of the role of invertebrate predators in regulating benthic macroinvertebrate communities in field microcosms are in progress.

A secondary purpose of this study was to identify the effects, if present, of both thermal effluents from a nuclear production reactor and other environmental characteristics (e.g., season and plot locality) on predator-prey interactions. Locations of experimental plots were chosen with this goal in mind. Results of concurrent field studies on the direct effects of elevated temperatures and plot locality on both odonate 


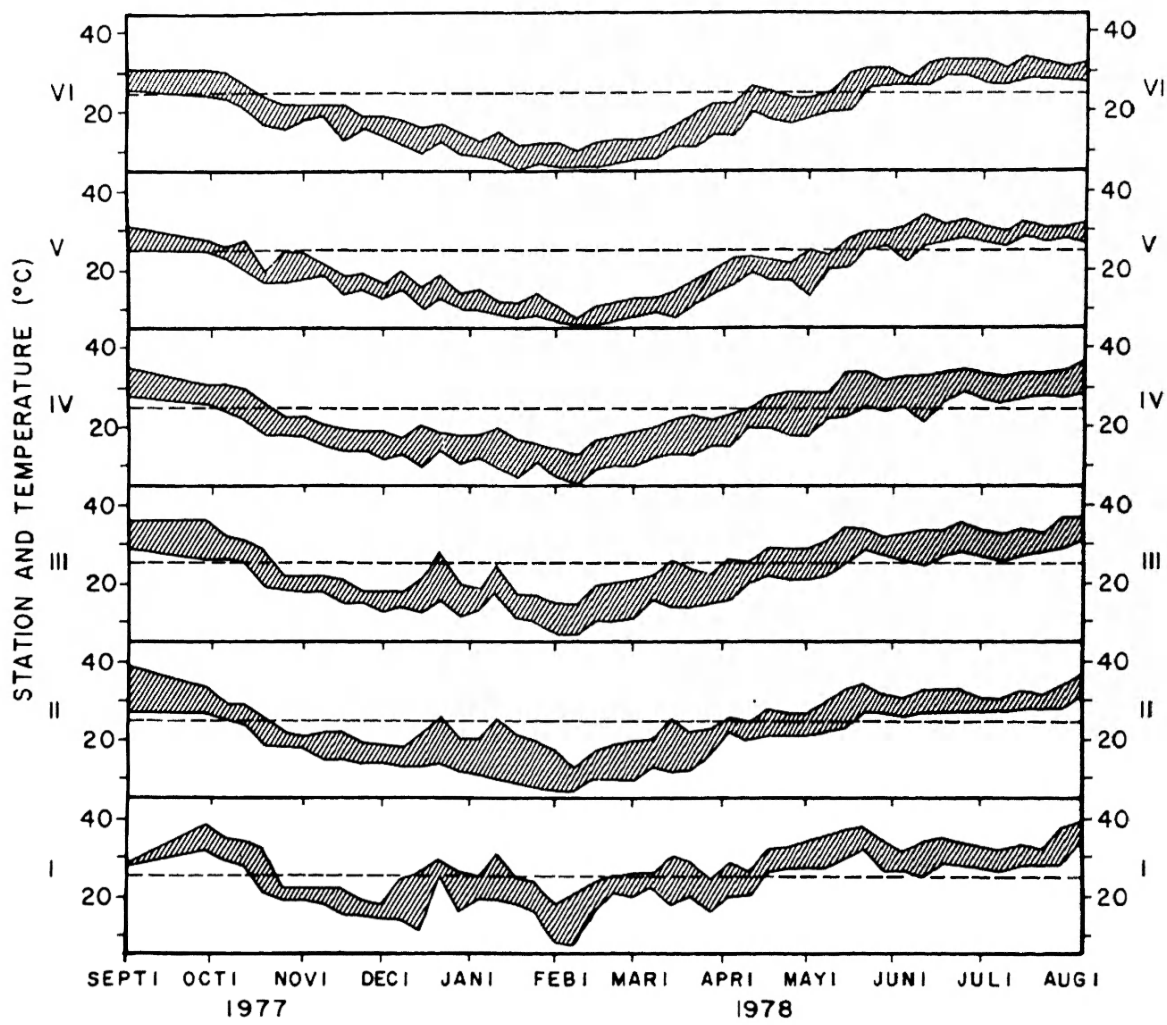

FIG. 2. Weekly temperature range at each experimental station (Roman numerals I-VI). Shaded portion bounded by maximum and minimum temperatures in ${ }^{\circ} \mathrm{C}$.

emergence and on the macroinvertebrate community in general will be described in detail in subsequent manuscripts.

\section{Study AREa}

Par Pond is a 22-yr-old, 1100-ha cooling reservoir ( maximum depth $=17 \mathrm{~m}$, mean depth $=6.1 \mathrm{~m}$ ) located on the Department of Energy's Savannah River Plant in Barnwell County, South Carolina (Fig. 1). The reservoir, which drains a relatively small watershed, receives water from the nearby Savannah River during the frequent but intermittent operation of a nuclear production reactor. Water pumped from the Savannah River causes the reservoir to be less acidic and more eutrophic than many of the surrounding coastal plain lakes. During reactor operation heated water flows from the reactor through a series of cooling ponds and enters Par Pond by a subsurface release at the "hot dam."

Six experimental stations were selected along a thermal gradient (Fig. 1). Stations were chosen to maximize similarity in wave exposure, substratum, and vegetation while simultaneously minimizing similarity in thermal regime. Stations were numbered consecutively by distance from the thermal release point, with stations I-IV located in the heated arm of Par Pond, and stations V-VI in areas of ambient temperatures. Maximum temperatures usually varied in- versely with station number (for stations I-IV) during reactor operation (Fig. 2).

For statistical purposes each station was divided into two blocks and each block contained three treatment and three control plots. In stations IV and V, blocks were situated on opposite sides of embayments; in other stations they were separated by as much distance as possible along the same shoreline. Within each block, treatment and control plots were arranged randomly in a linear sequence along the shoreline.

Substrata in all areas sampled were sandy near shore but gradually increased in silt-clay components in deeper waters. The littoral zone supported a large rooted macrophyte population during most of the year. Dominant vegetation in most areas sampled was either the spike-rush, Eleocharis acicularis, or the watermilfoil, Myriophyllum spicatum.

\section{Materials and Methods}

The role of vertebrate predators in regulating benthic macroinvertebrate community organization was evaluated by comparing uncaged control plots with caged treatment plots that excluded fish and turtles. Experiments were run seasonally and along a thermal gradient to analyze effects of seasonally "predictable" and nonseasonal, unpredictable thermal fluctuations on predator-prey relationships. 


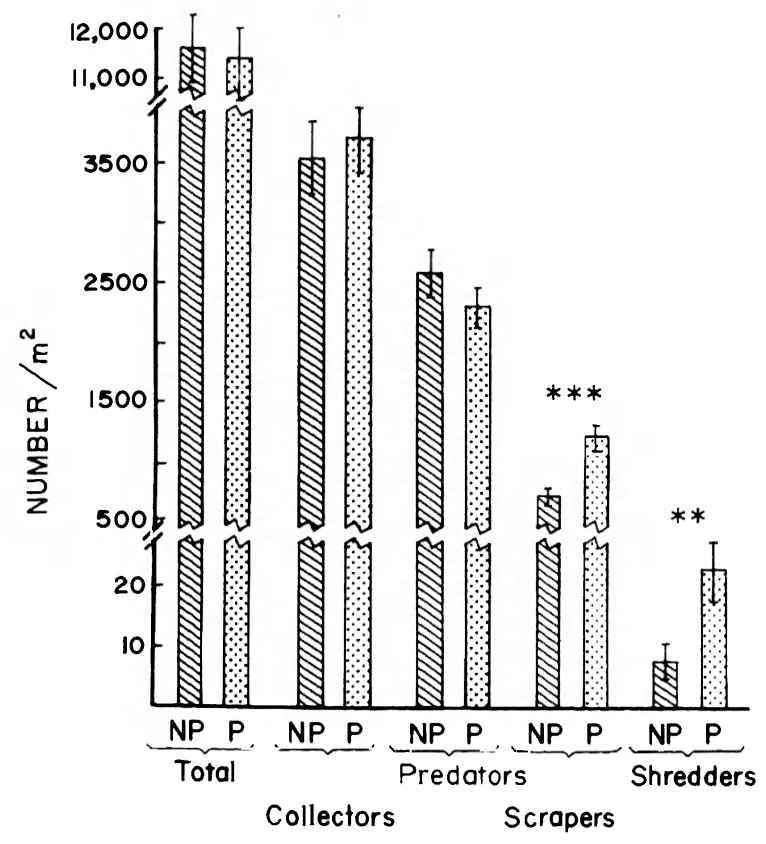

FIG. 3. Mean density of total macroinvertebrates and functional groups in number of organisms per square metre. Striped vertical bars are caged treatment results $(N P=$ no predators), stippled bars are from open control plots $(\mathrm{P}=$ predators present). Data were averaged from seasonal results. ${ }^{* * *}=P<.001,{ }^{* *}=P<.01$, between treatments.

Thirty-six, four-sided predator exclusion cages $(2 \times 2 \times 1 \mathrm{~m})$ were placed at a depth of $1 \mathrm{~m}$ or less in Par Pond (stations I-VI) so that all sides of the topless cages extended partially out of water. Cages were constructed of black, 3-mm mesh (1/8-inch) Dupont Vexar net supported by a frame of aluminum poles. Steel mesh (hardware cloth) was bent at a $90^{\circ}$ angle and fastened to an inner flap of netting at the bottom perimeter of the cage. By pushing the hardware cloth partially into the substratum and weighting it with bricks, the sides of the cages were sealed to the bottom. On occasion, some fish gained access when a side was lifted by waves; however, in those instances, fish were removed during weekly cage inspections. Cage sides were scrubbed periodically to reduce periphyte growth. An additional 36 control plots equal in size $\left(4 \mathrm{~m}^{2}\right)$ to the caged plots were delimited only by poles and were, therefore, totally accessible to fish. Partial cages with one open side were not employed as controls for cage effects because we wished to avoid increasing fish abundance by producing refuges for small predatory fish.

Cages were in place during three, 3-mo test periods: from 1 September to 1 December 1977, from 1 January to 1 April 1978, and from 1 May to 1 August 1978. Maximum-minimum temperatures were recorded weekly for $1 \mathrm{yr}$ (Fig. 2). Thermometers were placed on the bottom in each block at stations IV-VI but were placed between adjacent blocks at stations I-III.
Average temperatures were the mean of the maximum and minimum temperatures.

Benthic invertebrate samples were collected at the end of each 3-mo experimental period with a corer (area $=160 \mathrm{~cm}^{2}$, sample depth $\approx 15 \mathrm{~cm}$ ). On sampling dates two cores were removed from each cage and control plots for a total of 144 samples per period. To reduce possible cage edge effects, no samples were taken within $30 \mathrm{~cm}$ of the cage sides. Excess water from the cores was poured through a Number 35 United States Standard Sieve (500- $\mu \mathrm{m}$ mesh) and material retained was returned to the sample. Samples were preserved in ethyl alcohol and stained with Phloxine B (Fisher Scientific Company).

Macroinvertebrates were separated from bottom samples with an elutriator modified from Stewart (1975) (three airstones were added below the cylinder's sieve plate) using a Number 35 sieve, and then further sorted by hand in a white enamel tray. With the exception of chironomids, invertebrates were identified and counted using a dissecting microscope. Chironomids were cleared in heated $\mathrm{KOH}$, mounted in Hoyer's mounting medium, and identified to genus. For large samples, 50-60 chironomids were selected randomly for identification. Subsample size was determined initially with a species-area curve.

Taxa were grouped by trophic position according to feeding mechanisms after Merritt and Cummins (1978). Functional groups were shredders, collectors, scrapers, and predators. A taxon was assigned to more than one functional group in some cases. Separation of higher taxa into functional groups based on feeding mechanisms is only an approximation because variability in food-gathering strategies increases as the taxonomic level is raised above the species level. Within the context of community studies, however, functional grouping can serve as a valuable indicator of possible spatial and temporal changes within and between communities.

Nontransformed data were analyzed with the general linear model procedure (GLM) of the Statistical Analysis System (SAS) (Helwig and Council 1979) on an IBM-360 computer. Because the $F$ distribution utilized in the GLM test is ". . . relatively unaffected by lack of data normality and heterogeneity of variance ..." (Kirk 1968:63), transformation of data was not considered unless the number of replicates was $<25$ $G_{1}{ }^{2}$ (Cochran 1963:41), where $G_{1}$ is Fisher's measure of skewness (Fisher 1932). Alpha levels of 0.05 or less indicated significant treatment effects.

\section{RESULTS}

\section{Density of individuals and functional groups}

Mean total density of macroinvertebrates was not significantly related to the presence or absence of vertebrate predators (Fig. 3, $t=0.184, P>.05$ ). The mean number of macroinvertebrates did not vary sig- 
TABLE 1. Seasonal changes in abundance of the most common benthic macroinvertebrates in response to the presence or absence of vertebrate predation. Abundance expressed as mean number of individuals per square metre, with the standard error of the mean in parentheses.

\begin{tabular}{|c|c|c|c|c|c|c|}
\hline \multirow[b]{2}{*}{ Treatment } & \multicolumn{2}{|c|}{1 Sept-1 Dec } & \multicolumn{2}{|c|}{1 Jan-1 April } & \multicolumn{2}{|c|}{1 May-1 Aug } \\
\hline & Predators & No predators & Predators & No predators & Predators & No predators \\
\hline All invertebrates & $\begin{array}{r}13795.3 \\
(1280.5)\end{array}$ & $\begin{array}{c}14696.3 \\
(1452.4)\end{array}$ & $\begin{array}{l}6042.8 \\
(859.2)\end{array}$ & $\begin{array}{l}7674.1 \\
(859.4)\end{array}$ & $\begin{array}{r}12026.9 \\
(797.4)\end{array}$ & $\begin{array}{c}10866.3 \\
\quad(707.4)\end{array}$ \\
\hline \multicolumn{7}{|l|}{ Platyhelminthes } \\
\hline Turbellaria & $36.8(9.7)$ & $9.5(3.4)$ & $77.3(29.5)$ & $20.8(5.9)$ & $2.6(1.5)$ & $0.9(0.9)$ \\
\hline \multicolumn{7}{|l|}{ Annelida } \\
\hline $\begin{array}{l}\text { Oligochaeta } \\
\text { Hirudinea }\end{array}$ & $\begin{array}{c}669.5(89.8) \\
18.0(6.2)\end{array}$ & $\begin{array}{c}509.5(60.2) \\
5.2(2.4)\end{array}$ & $\begin{array}{r}491.8(65.3) \\
41.1(16.9)\end{array}$ & $\begin{array}{c}372.0(68.5) \\
22.3(9.2)\end{array}$ & $\begin{array}{c}964.4(88.8) \\
25.2(7.2)\end{array}$ & $\begin{array}{c}662.3(104.5) \\
7.8(2.4)\end{array}$ \\
\hline \multicolumn{7}{|l|}{ Mollusca } \\
\hline \multicolumn{7}{|l|}{ Pelecypoda } \\
\hline $\begin{array}{l}\text { Unionidae } \\
\text { Sphaeriidae }\end{array}$ & $\begin{aligned} 3.4 & (2.1) \\
263.7 & (53.8)\end{aligned}$ & $\begin{array}{c}2.6(1.5) \\
164.1(42.4)\end{array}$ & $\begin{aligned} 4.9 & (2.8) \\
287.8 & (133.2)\end{aligned}$ & $\begin{array}{c}1.5(1.5) \\
175.6(65.3)\end{array}$ & $\begin{array}{c}16.5(4.8) \\
1274.3(234.2)\end{array}$ & $\begin{array}{l}0.0 \\
1179.7(215.6)\end{array}$ \\
\hline \multicolumn{7}{|l|}{ Gastropoda } \\
\hline $\begin{array}{l}\text { Amnicola } \\
\text { Gyraulus } \\
\text { Helisoma anceps } \\
\text { H. trivolvis } \\
\text { Menetus } \\
\text { Physa }\end{array}$ & $\begin{array}{c}68.5(47.3) \\
86.5(15.4) \\
169.5(33.2) \\
811.6(120.9) \\
99.3(27.6) \\
368.9(55.6)\end{array}$ & $\begin{array}{c}20.0(12.7) \\
32.1(16.9) \\
17.4(5.6) \\
125.9(54.7) \\
13.9(7.7) \\
144.1(46.3)\end{array}$ & $\begin{array}{c}3.3(3.3) \\
26.3(8.0) \\
41.1(9.8) \\
403.0(65.8) \\
151.3(48.6) \\
292.8(41.0)\end{array}$ & $\begin{array}{r}1.5(1.5) \\
26.8(10.2) \\
29.8(13.0) \\
331.8(54.1) \\
61.0(24.5) \\
383.9(64.6)\end{array}$ & $\begin{array}{r}261.3(81.8) \\
41.7(12.5) \\
49.5(16.1) \\
203.1(26.5) \\
13.9(3.3) \\
167.5(26.1)\end{array}$ & $\begin{aligned} 83.3 & (33.0) \\
8.7 & (3.3) \\
56.4 & (13.9) \\
230.0 & (27.7) \\
4.3 & (1.9) \\
235.2 & (42.5)\end{aligned}$ \\
\hline \multicolumn{7}{|l|}{ Arthropoda } \\
\hline $\begin{array}{l}\quad \text { Hyalella azteca } \\
\text { Ostracoda } \\
\text { Hydracarina (Acari) }\end{array}$ & $\begin{array}{c}158.4(89.1) \\
1595.0(221.5) \\
489.7(141.1)\end{array}$ & $\begin{array}{r}120.6(60.2) \\
1526.9(272.0) \\
379.3(125.6)\end{array}$ & $\begin{array}{c}62.5(39.3) \\
403.0(143.8) \\
634.9(164.0)\end{array}$ & $\begin{array}{c}4.5(2.5) \\
897.3(282.7) \\
602.7(165.6)\end{array}$ & $\begin{array}{c}237.0(76.9) \\
2016.5(335.0) \\
201.4(19.9)\end{array}$ & $\begin{array}{c}42.5(18.3) \\
3124.1(518.3) \\
195.3(23.6)\end{array}$ \\
\hline \multicolumn{7}{|l|}{ Odonata } \\
\hline $\begin{array}{l}\text { Celithemis } \\
\text { Epicordulia } \\
\text { Erythemis } \\
\text { Erythrodiplax } \\
\text { Ladona } \\
\text { Libellula } \\
\text { Pachydiplax } \\
\text { Perithemis } \\
\text { Tetragoneuria } \\
\text { Gomphidae } \\
\text { Enallagma } \\
\text { Ischnura }\end{array}$ & $\begin{array}{c}26.9(7.2) \\
0.0 \\
17.4(4.8) \\
1.7(1.7) \\
0.0 \\
23.4(6.0) \\
7.8(3.5) \\
0.9(0.9) \\
1.7(1.2) \\
0.8(0.8) \\
16.3(5.2) \\
47.1(46.2)\end{array}$ & $\begin{array}{l}21.7(4.5) \\
2.6(1.5) \\
33.8(8.9) \\
1.7(1.2) \\
0.9(0.9) \\
7.8(3.0) \\
4.3(2.2) \\
0.0 \\
2.6(1.9) \\
0.0 \\
2.6(1.5) \\
0.0\end{array}$ & $\begin{array}{l}8.2(5.4) \\
0.0 \\
4.9(3.6) \\
0.0 \\
0.0 \\
1.6(1.6) \\
3.3(3.3) \\
1.6(1.6) \\
1.6(1.6) \\
0.0 \\
29.6(8.4) \\
3.3(2.3)\end{array}$ & $\begin{array}{l}20.8(5.5) \\
1.5(1.5) \\
14.9(5.6) \\
0.0 \\
0.0 \\
1.5(1.5) \\
0.0 \\
0.0 \\
0.0 \\
0.0 \\
14.9(4.2) \\
0.0\end{array}$ & $\begin{array}{l}41.7(8.1) \\
10.4(3.5) \\
27.8(6.5) \\
0.0 \\
1.7(1.2) \\
25.2(5.8) \\
36.4(7.2) \\
13.9(4.8) \\
3.5(1.7) \\
2.4(1.5) \\
56.4(11.5) \\
0.0\end{array}$ & $\begin{array}{c}38.2(11.4) \\
19.1(10.1) \\
39.1(11.6) \\
11.3(9.7) \\
13.0(9.6) \\
30.4(10.7) \\
33.0(11.0) \\
12.2(9.6) \\
12.2(9.6) \\
7.2(6.8) \\
21.7(6.4) \\
0.0\end{array}$ \\
\hline \multicolumn{7}{|l|}{ Ephemeroptera } \\
\hline $\begin{array}{l}\text { Caenis } \\
\text { Baetis-Callibaetis } \\
\text { Lepidoptera } \\
\text { Hemiptera }\end{array}$ & $\begin{array}{c}993.2(257.9) \\
1.7(1.2) \\
16.5(5.5) \\
0.8(0.8)\end{array}$ & $\begin{array}{l}441.8(90.5) \\
0.0 \\
4.3(2.2) \\
0.0\end{array}$ & $\begin{array}{l}42.8(10.3) \\
0.0 \\
0.0 \\
0.0\end{array}$ & $\begin{array}{c}125.0(35.2) \\
0.0 \\
0.0 \\
0.0\end{array}$ & $\begin{array}{c}607.6(103.1) \\
53.0(12.1) \\
37.3(10.3) \\
0.9(0.9)\end{array}$ & $\begin{array}{c}346.4(50.5) \\
39.9(9.0) \\
11.3(6.7) \\
0.9(0.9)\end{array}$ \\
\hline \multicolumn{7}{|l|}{ Trichoptera } \\
\hline $\begin{array}{l}\text { Oecetis } \\
\text { Oxyethira } \\
\text { Orthotrichia } \\
\text { Polycentropus }\end{array}$ & $\begin{aligned} 17.1(7.6) \\
142.1(21.8) \\
164.4(23.3) \\
69.3(23.9)\end{aligned}$ & $\begin{array}{r}9.5(3.2) \\
275.2(46.8) \\
201.4(46.3) \\
42.5(14.2)\end{array}$ & $\begin{array}{r}4.9(2.8) \\
16.4(6.5) \\
6.6(3.2) \\
18.1(9.4)\end{array}$ & $\begin{array}{c}7.4(4.8) \\
56.5(14.7) \\
6.0(3.6) \\
8.9(6.2)\end{array}$ & $\begin{array}{r}37.3(6.2) \\
7.8(3.5) \\
7.8(2.7) \\
13.0(5.9)\end{array}$ & $\begin{array}{r}23.4(7.0) \\
26.9(7.1) \\
17.4(5.6) \\
8.7(3.1)\end{array}$ \\
\hline \multicolumn{7}{|l|}{ Coleoptera } \\
\hline $\begin{array}{l}\text { Hydroporus } \\
\text { Hydrovatus } \\
\text { Berosus } \\
\text { Haliplus } \\
\text { Peltodytes }\end{array}$ & $\begin{array}{c}18.2(6.7) \\
0.0 \\
105.9(16.6) \\
1.7(1.2) \\
7.7(4.0)\end{array}$ & $\begin{array}{c}26.9(6.2) \\
0.0 \\
76.4(11.2) \\
1.7(1.2) \\
7.4(3.8)\end{array}$ & $\begin{array}{l}0.0 \\
1.6(1.6) \\
9.0(4.5) \\
1.6(1.6) \\
46.0(11.2)\end{array}$ & $\begin{aligned} & 3.0(2.1) \\
& 4.5(3.3) \\
& 26.8(8.8) \\
& 2.2(1.8) \\
& 35.7(11.9)\end{aligned}$ & $\begin{array}{c}0.0 \\
0.0 \\
239.6(25.2) \\
2.2(1.4) \\
5.2(2.4)\end{array}$ & $\begin{array}{c}0.0 \\
0.0 \\
325.5(34.5) \\
4.8(4.0) \\
0.9(0.9)\end{array}$ \\
\hline \multicolumn{7}{|l|}{ Diptera } \\
\hline $\begin{array}{l}\text { Ceratopogonidae } \\
\text { Chironomidae } \\
\text { Tabanidae }\end{array}$ & $\begin{array}{c}1565.1(172.9) \\
6047.9(739.6) \\
7.3(3.9)\end{array}$ & $\begin{array}{c}2746.5(344.9) \\
7490.4(887.2) \\
3.5(1.9)\end{array}$ & $\begin{array}{c}764.8(104.4) \\
1769.7(482.2) \\
4.9(2.8)\end{array}$ & $\begin{aligned} 773.8 & (105.0) \\
3309.5 & (610.8) \\
1.5 & (1.5)\end{aligned}$ & $\begin{array}{c}1539.1(192.0) \\
3359.4(341.2) \\
5.5(2.6)\end{array}$ & $\begin{array}{c}1314.2(125.9) \\
2299.5(190.6) \\
4.6(2.0)\end{array}$ \\
\hline
\end{tabular}




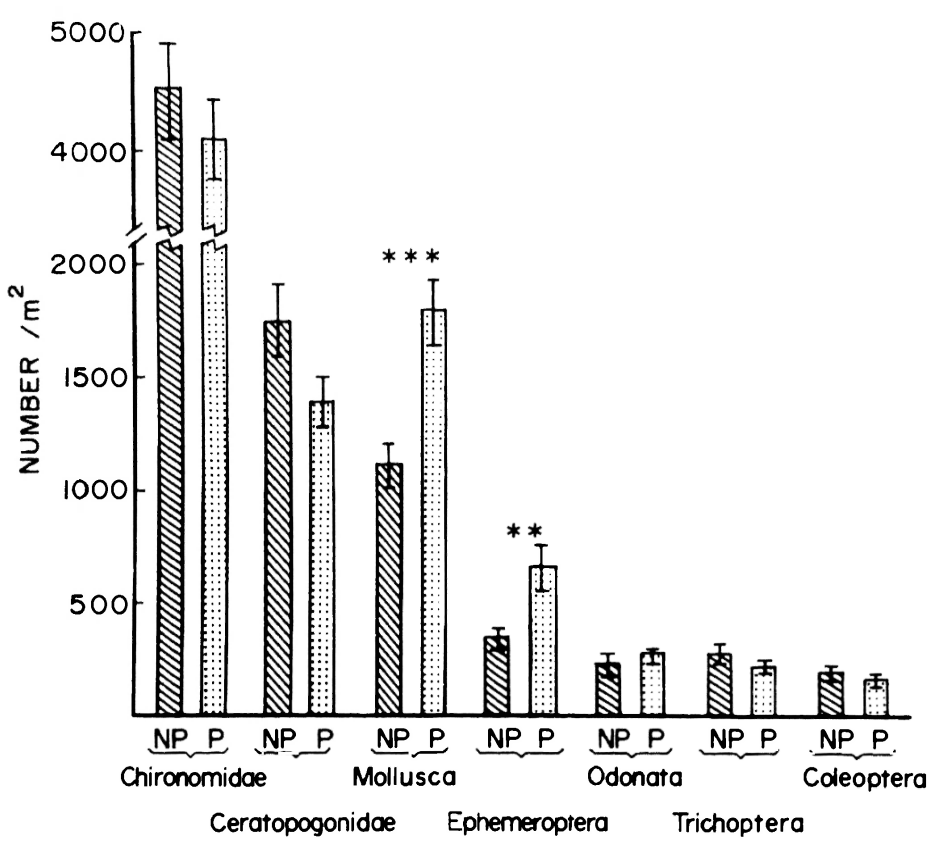

FIG. 4. Mean density in number of organisms per square metre for various taxonomic groups. Striped bars are caged treatment results $(\mathrm{NP}=$ no predators), stippled bars are from open control plots $(\mathrm{P}=$ predators present $)$. Data were averaged from seasonal results. ${ }^{* * *}=P<.001, * *=P<.01$.

nificantly on a yearly basis between caged (11 611 macroinvertebrates $\left./ \mathrm{m}^{2}\right)$ and open control plots (11 438 macroinvertebrates $\left./ \mathrm{m}^{2}\right)$, nor between caged and control plots during any 3 -mo test period ( $F$ test, $P>.05$ for each period, Table 1).

Contributing most to the mean macroinvertebrate density were two dipteran families, Chironomidae and Ceratopogonidae, as well as the molluscan order Gastropoda (Table 1). Of these three taxa only gastropods were affected significantly by treatment $(P<.05$, Fig. 4) although the increase in numbers of biting midges (Ceratopogonidae), when vertebrate predators were excluded, was almost significant $(P<.06)$. The apparent significant depression in molluscan numbers in the absence of vertebrate predation (Fig. 3) may have been a sampling problem associated with a "cage effect." Many snails originating from the cage interior migrated to the cage sides, which were not sampled quantitatively. Hence, core samples within cages may have erroneously indicated that snail abundance decreased as a direct or indirect result of the absence of vertebrate predators. The response of true midges (Chironomidae) to vertebrate predation will be described in detail in a later paper. In general, however, the abundance of midges and the average individual size (head length) remained constant between cage and control plots.

The densities of the two functional groups with the most organisms, collectors and predators, were not significantly affected by treatment, whereas the abundance of organisms in the two groups with the fewest individuals, scrapers and shredders, were significantly depressed when vertebrate predators were absent
(Fig. 3). The slight trend towards increased numbers of invertebrate predators in the absence of fish and turtles (Fig. 3) may suggest that invertebrate predators were replacing the top aquatic carnivores in their functional role. If real, this trend for substitution of vertebrate with invertebrate predators could have masked signficant treatment effects. Numbers of predatory Ceratopogonidae (Fig. 4) and Chironomidae (J. H. Thorp and E. A. Bergey, personal observation) increased slightly (nonsignificant), but this trend was not evident for predatory dragonflies, damselflies (Odonata), or beetles (Coleoptera) (Fig. 4). Because snails contributed the bulk of the "scraper" functional group (Table 1), the significant reduction within cages may have been a sampling error as described earlier. It is not clear why the number of shredders decreased in the absence of vertebrate predators (Fig. 3).

\section{Taxa richness}

The mean number of macroinvertebrate taxa per sample was significantly less when vertebrate predators were excluded, whether analyzed for all test periods combined $(P<.0001$, Fig. 5$)$ or for each period individually $(P<.0001$ and .0189 for the periods 1 September-1 December and 1 May-1 August, respectively) except for $1 \mathrm{Jan}-1$ April $(P>.05)$. As most of this difference in mean number of taxa between treatment and control plots was accounted for by gastropods (Fig. 6), the results suggest that a cage effect (as described earlier), rather than a positive effect from vertebrate predation, was responsible.

The number of taxa in all functional groups of Chironomidae were not significantly affected by predator 
treatment (Wilcoxon two-sample test) except for the few shredder genera $(P<.01)$. However, with the exception of collectors, all functional groups of macroinvertebrates were signficantly reduced within cages (Fig. 5). Possibly the cages inhibited both lateral recruitment of larvae and egg deposition from some species of flying adults. Of the taxa in Fig. 6 only the damselflies and snails were reduced significantly within cages.

\section{Location and temperature effects}

The relationship between vertebrate predation and the density and taxa richness of macroinvertebrates did not significantly vary seasonally with respect either to location of plots or to average and maximum water temperatures during test periods. When data from caged and control plots were pooled, however, both location and water temperature individually had direct impacts on the benthic community. Density of macroinvertebrates was significantly related to maximum water temperature for all test periods $(P<.01)$ and to average water temperature for all periods $(P<$ .05 ) except 1 September-1 December. Taxa richness was significantly affected by average water temperature only during the periods 1 September-1 December $(P<.001)$ and 1 May-1 August $(P<.0001)$, and by maximum water temperature only during the latter period $(P<.0001)$.

Despite attempts to minimize nonthermal differences between and within stations, biotic (abundance and diversity of vertebrate predators and aquatic vegetation) and abiotic conditions (substrata, wave exposure, etc.) differed to varying degrees between localities. In addition to the significant relationships between plot location and both density $(P<.001$ for all test periods) and taxa richness of macroinvertebrates $(P<.0001$ for all periods except 1 January-1 April, $P>.05)$, the interaction between location and treatment (predator vs. no predator) was significant in all periods for taxa richness $(P<.05)$ but only during the period 1 May-1 August for density $(P<.01)$. A detailed analysis of the effects of biotic (nonpredatory) and abiotic factors on abundance and taxa richness will be presented in a future paper.

\section{Discussion}

Although it is evident from previous studies that fish (Bennett and Gibbons 1972, Clugston 1973) and turtles (Parmenter 1980) in Par Pond consumed benthic organisms, results of this study do not suggest that vertebrate predation was the fundamental parameter organizing the benthic macroinvertebrate community in the littoral zone of this reservoir. Mean density of total macroinvertebrates was not significantly affected by treatment (vertebrate predator exclusion vs. control) during any season. The abundance of midges (Chironomidae and Ceratopogonidae), which dominated the benthic community numerically, and their mean indi-

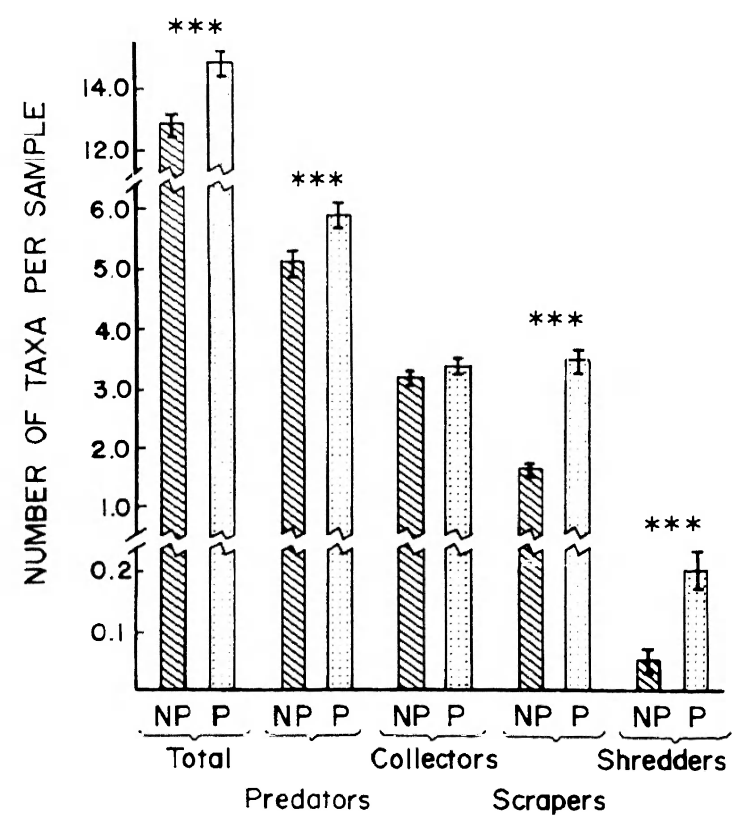

Fig. 5. Mean taxa richness in number of taxa per sample core (160 cm" cross-sectional area) for total macroinvertebrates and functional groups. Striped bars are caged treatment results (NP $=$ no predators), stippled bars are from open control plots $(P=$ predators present). Data were averaged from seasonal results. ${ }^{* * *}=P<.001$, between treatments.

vidual size remained constant between cage and control plots. However, a tendency for increased density of invertebrate predators within cages may suggest that invertebrates were replacing fish and perhaps turtles as the top aquatic predators on the benthic community. Further and possibly longer experiments are necessary to demonstrate whether this trend was real. Evidence relating the effects of treatment on taxa richness was, unfortunately, not conclusive, but suggests that vertebrate predators were not regulating the organization of the benthic community. Taxa richness of total macroinvertebrates decreased rather than increased within cages (probably due to an artificial cage effect as discussed previously). The numbers of taxa in the dominant functional groups of Chironomidae were not significantly affected by predator treatment. However, with the exception of collectors, all functional groups of macroinvertebrates were significantly reduced within cages. Hence, some taxa were eliminated when vertebrate predators were absent, but this loss was not compensated for by increased numbers of potentially competitive taxa as was found by Paine (1966) and Dayton (1971) in rocky intertidal environments.

The predator-prey relationships that we observed through time for all stations were reasonably consistent despite any natural fluctuations in the abundance and diversity of bottom-feeding fishes between stations that may have occurred seasonally. The time required to quantify seasonal differences in abundance 


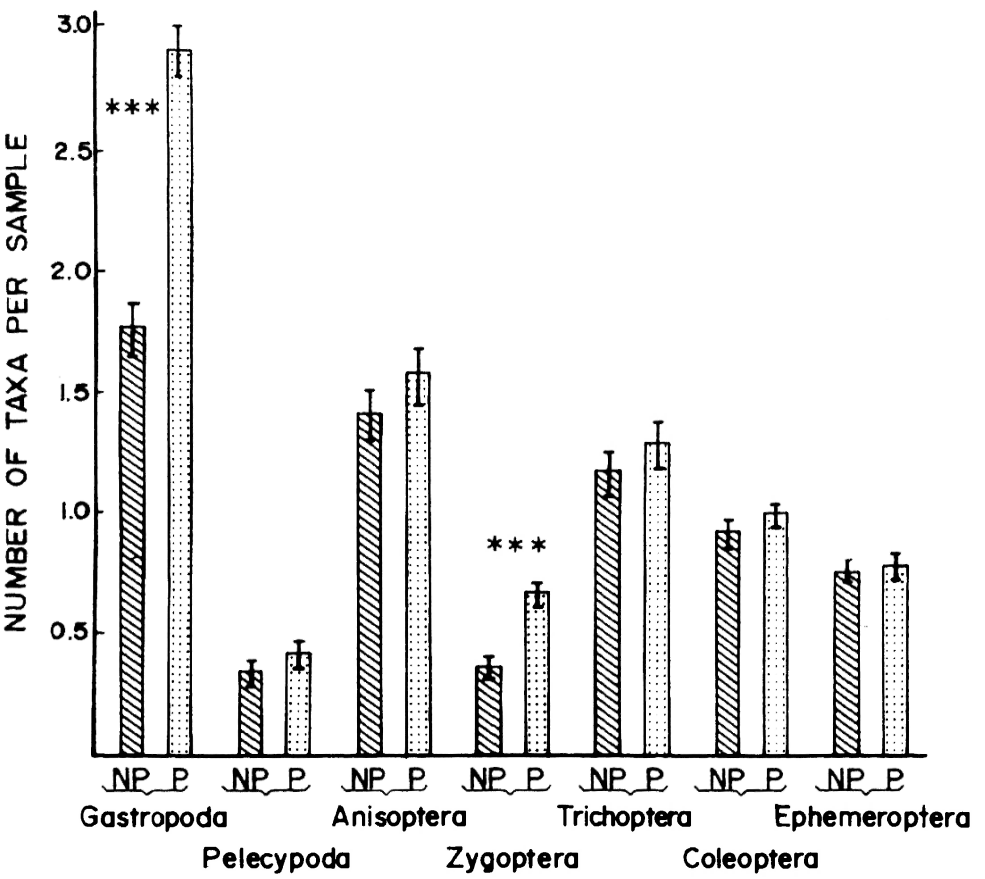

FIG. 6. Mean taxa richness in number of taxa per sample core $\left(160 \mathrm{~cm}^{2}\right.$ cross-sectional area $)$ for certain classes of Mollusca (Gastropoda and Pelecypoda) or orders of Insecta. Striped bars are caged treatment results (NP = no predators), stippled bars are from open control plots $(\mathrm{P}=$ predators present $)$. Data were averaged from seasonal results. ${ }^{* * *}=P<$ .001 , between treatments.

and species richness of vertebrate predators for each station and block was considered prohibitive in our study. However, on the basis of a previous study (Clugston 1973) these differences between stations were considered to be relatively small. All of the 27 species of fish (including many bottom-feeding varieties) reported for Par Pond were collected in both ambient and heated areas (Clugston 1973). Included in this list were the sunfish species Lepomis auritus, $L$. gulosus, L. macrochirus, L. microlophus, and $L$. punctatus, as well as the largemouth bass Micropterus salmoides. If the percentage of bottom-feeding fishes and turtles were reduced in the hottest cove or increased in warm coves (thermal enhancement rather than stress), then the difference between caged and control plots would either be diminished or magnified, respectively, relative to ambient areas. However, any relative abundance differences which may have existed had no apparent significant effect on the general relationship between predator treatment and prey response in our study.

One of the original goals of our study was to understand whether seasonal alterations in the composition of benthic communities along thermal gradients were a direct response to thermal stress (or enhancement) or, instead, an indirect effect produced by changes in predator-prey relationships. Our results indicate that the general relationship between predator treatment and community response (density and taxa richness) was generally unaffected by temperature fluctuations from thermal effluents or seasonal changes. In contrast, when data from caged and open plots were pooled, both location and water temperature individually had significant impacts on the benthic community.

Except for studies on planktonic communities (e.g., Dodson 1970, Hall et al. 1970), most experiments on the importance of vertebrate predation in structuring freshwater communities have been either inconclusive or have failed to show any appreciable effect comparable to the results found in rocky intertidal systems (Paine 1966, Dayton 1971). Hall et al. (1970) manipulated the density of bluegills, Lepomis macrochirus, in experimental ponds. Fish predation had no demonstrable effect on total benthic biomass but did influence emergence rate. Ball and Hayne (1952) measured abundances of benthic lake invertebrates for $2 \mathrm{yr}$, then poisoned the fish and recorded invertebrate abundance for an additional year. They concluded that significant increases in invertebrate biomass during the $3 \mathrm{rd}$ yr resulted from fish removal. Invertebrate abundance also increased significantly, however, between the 1st 2 yr when fish were present. Hayne and Ball (1956) found that the standing crop of those benthic invertebrates regularly consumed by fish was depressed while the rate of production increased in two ponds following introduction of sunfish. However, the abundance of benthic macroinvertebrates in both ponds also decreased in the absence of fish. The results of the latter two experiments, in our opinion, did not demonstrate that fish regulated the benthic community.

With a few notable exceptions (Hall et al. 1970, 
Benke 1978, Peckarsky 1979) most field experiments on the importance of invertebrate predation in freshwater benthic systems have focused on prey at the population or guild level (e.g., Kajak 1963, Eisenberg 1966) rather than on the entire benthic community. Hall et al. (1970) seined experimental ponds to remove large invertebrate predators. The mean prey biomass showed little response to reduced predation in 1965 and through half of the 1966 sampling period, although biomass later increased in ponds with reduced densities of invertebrate predators. They suggested that invertebrates predation was affecting the ratio of the two dominant benthic organisms, the midge Chironomus and the mayfly Caenis. In a well-conceived field experiment, Benke (1978) manipulated abundance of larval dragonfly populations in cages (which excluded fish) to determine importance of interactions among odonates and the effects of dragonflies on their prey. He reported that, ". . . abundance of early emerging odonates plays some role in prey (especially Tanypodinae) abundance." $\mathrm{He}$ also suggested that, ". . . the primary determinant of community structure and production is an interaction between refuge level and predation rate."

On the basis of our experiments and other community studies in which natural populations of vertebrate and invertebrate predators have been manipulated, we propose a general hypothesis that individual species of keystone benthic predators do not occur in the littoral zone of freshwater lentic environments with soft bottoms. We suspect that many of the environmental conditions characteristic of soft-bottom, lentic systems that may have inhibited development of keystone predators are also applicable to some soft-bottom lotic environments and even to some softbottom marine or estuarine systems. If keystone predators are found in some lentic soft-bottom environments, it would be instructive to note which of the following arguments supporting our general hypothesis is invalid and to distinguish the biotic or abiotic characteristics of that system which have promoted evolution or maintenance of a keystone predator.

A keystone species in lentic, soft-bottom environments would, by definition, be capable of disproportionately affecting patterns of prey species occurrence, distribution, and density by preventing monopolization of the major environmental requisites by one prey species (Paine 1966). Disproportionate dominance by one predator and monopolization by one prey species in the littoral zone of lentic systems are unlikely, in our opinion. The following four arguments supporting this premise and our general hypothesis were formed on the basis of personal observations and general literature evidence rather than on direct quantitative data. Direct evidence based on pertinent comparative studies of marine, estuarine and freshwater communities is presently unavailable.

First, environmental heterogeneity should reduce predator efficiency relative to that found in rocky intertidal systems where keystone predation may be present. Although low in heterogeneity, soft-bottom environments provide more refuges in three-dimensional space than afforded by the generally two-dimensional space of rocky intertidal zones. Attached macrophytes add both heterogeneity and refuges to soft-bottom systems.

Second, relative food web complexity should reduce the community importance of an individual predator species. Food web complexity is associated with lower relative abundance of individual predator species. The greater complexity reduces the ability of one predator taxon to prevent monopolization of resources by one dominant prey. Reduced relative abundance of individual predator and prey species also lowers the probability that a potentially dominant prey would be preferentially or exclusively consumed by a keystone species (which may be necessary to prevent monopolization [Paine 1966]).

Third, the apparent relatively greater resource partitioning of space and food in the freshwater littoral zone hinders monopolization of rate-limiting environmental resources by a single dominant prey species. Dominant prey species in rocky intertidal zones are filter-feeding occupants of primary substratum and may be restricted to only a few species (Paine 1966, $1969 a, b$, Dayton 1971). Greater food web and habitat complexities in freshwater littoral zones provide additional niche axes for both competition and coexistence, thus increasing the difficulty for one prey species to dominate the community. Monospecific patches of benthic macroinvertebrates are rarely found in unpolluted freshwater lentic environments (J. H. Thorp, personal observation).

Fourth, the effects of predation may not be extensive enough in time or area to provide sufficient resource space (and thus food) for exploitation by fugitive species. In some rocky intertidal systems starfish and other predators or herbivores increase species diversity and regulate the community by creating open patches for exploitation by motile larvae of less dominant species such as sessile adult barnacles (Dayton 1971). In freshwater soft-bottom systems, however, open patches are probably less frequently created. When they are available, lateral colonization from the highly motile organisms in the contiguous substrata should rapidly deplete freed resources.

If our hypothesis is generally true for soft-bottom littoral systems, then two questions arise. First, what conditions would have to be present to promote the development or maintenance of a keystone species in these environments? And second, what is the importance of nonkeystone predation in these systems?

If a prey were a "foundation species" (Dayton 1972), then a carnivore or an herbivore that could control that prey population would be a keystone species for the benthic community. Foundation species (Day- 


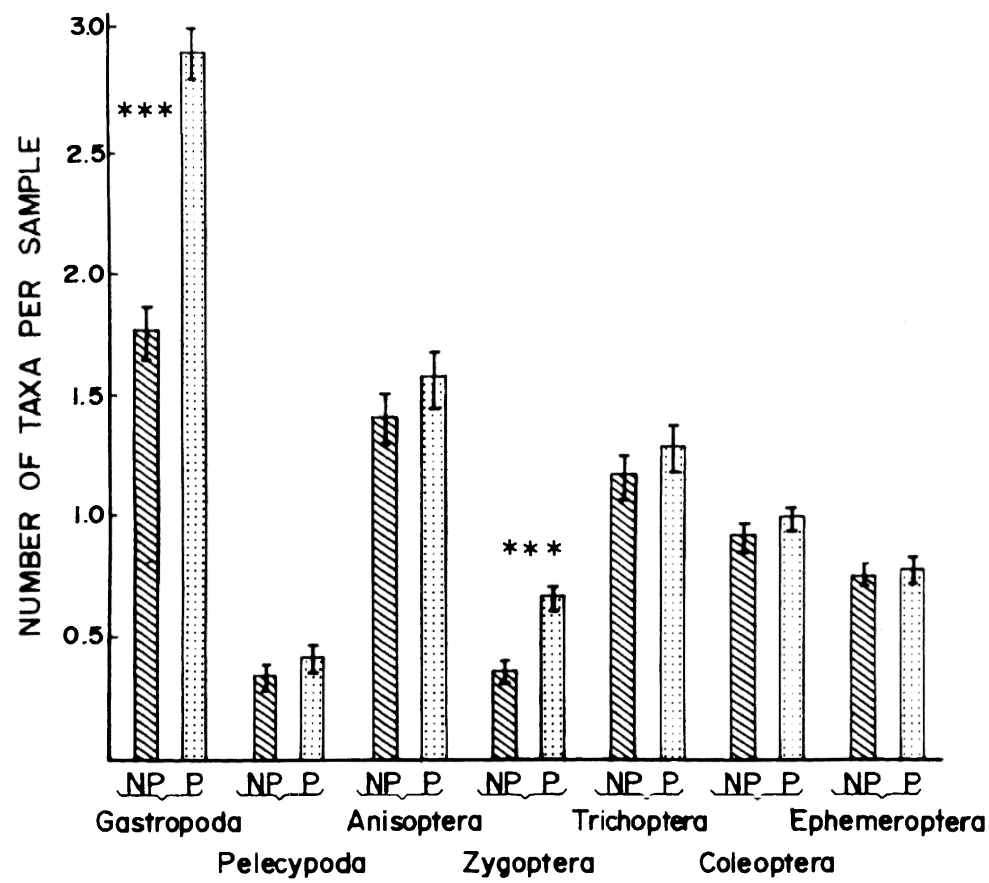

FIg. 6. Mean taxa richness in number of taxa per sample core $\left(160 \mathrm{~cm}^{2}\right.$ cross-sectional area) for certain classes of Mollusca (Gastropoda and Pelecypoda) or orders of Insecta. Striped bars are caged treatment results (NP = no predators), stippled bars are from open control plots $(\mathrm{P}=$ predators present $)$. Data were averaged from seasonal results. ${ }^{* * *}=P<$ .001 , between treatments.

and species richness of vertebrate predators for each station and block was considered prohibitive in our study. However, on the basis of a previous study (Clugston 1973) these differences between stations were considered to be relatively small. All of the 27 species of fish (including many bottom-feeding varieties) reported for Par Pond were collected in both ambient and heated areas (Clugston 1973). Included in this list were the sunfish species Lepomis auritus, $L$. gulosus, L. macrochirus, L. microlophus, and $L$. punctatus, as well as the largemouth bass Micropterus salmoides. If the percentage of bottom-feeding fishes and turtles were reduced in the hottest cove or increased in warm coves (thermal enhancement rather than stress), then the difference between caged and control plots would either be diminished or magnified, respectively, relative to ambient areas. However, any relative abundance differences which may have existed had no apparent significant effect on the general relationship between predator treatment and prey response in our study.

One of the original goals of our study was to understand whether seasonal alterations in the composition of benthic communities along thermal gradients were a direct response to thermal stress (or enhancement) or, instead, an indirect effect produced by changes in predator-prey relationships. Our results indicate that the general relationship between predator treatment and community response (density and taxa richness) was generally unaffected by temperature fluctuations from thermal effluents or seasonal changes. In contrast, when data from caged and open plots were pooled, both location and water temperature individually had significant impacts on the benthic community.

Except for studies on planktonic communities (e.g., Dodson 1970, Hall et al. 1970), most experiments on the importance of vertebrate predation in structuring freshwater communities have been either inconclusive or have failed to show any appreciable effect comparable to the results found in rocky intertidal systems (Paine 1966, Dayton 1971). Hall et al. (1970) manipulated the density of bluegills, Lepomis macrochirus, in experimental ponds. Fish predation had no demonstrable effect on total benthic biomass but did influence emergence rate. Ball and Hayne (1952) measured abundances of benthic lake invertebrates for $2 \mathrm{yr}$, then poisoned the fish and recorded invertebrate abundance for an additional year. They concluded that significant increases in invertebrate biomass during the $3 \mathrm{rd}$ yr resulted from fish removal. Invertebrate abundance also increased significantly, however, between the 1 st $2 \mathrm{yr}$ when fish were present. Hayne and Ball (1956) found that the standing crop of those benthic invertebrates regularly consumed by fish was depressed while the rate of production increased in two ponds following introduction of sunfish. However, the abundance of benthic macroinvertebrates in both ponds also decreased in the absence of fish. The results of the latter two experiments, in our opinion, did not demonstrate that fish regulated the benthic community.

With a few notable exceptions (Hall et al. 1970, 
Benke 1978, Peckarsky 1979) most field experiments on the importance of invertebrate predation in freshwater benthic systems have focused on prey at the population or guild level (e.g., Kajak 1963, Eisenberg 1966) rather than on the entire benthic community. Hall et al. (1970) seined experimental ponds to remove large invertebrate predators. The mean prey biomass showed little response to reduced predation in 1965 and through half of the 1966 sampling period, although biomass later increased in ponds with reduced densities of invertebrate predators. They suggested that invertebrates predation was affecting the ratio of the two dominant benthic organisms, the midge Chironomus and the mayfly Caenis. In a well-conceived field experiment, Benke (1978) manipulated abundance of larval dragonfly populations in cages (which excluded fish) to determine importance of interactions among odonates and the effects of dragonflies on their prey. He reported that, ". . . abundance of early emerging odonates plays some role in prey (especially Tanypodinae) abundance." He also suggested that, ". . . the primary determinant of community structure and production is an interaction between refuge level and predation rate."

On the basis of our experiments and other community studies in which natural populations of vertebrate and invertebrate predators have been manipulated, we propose a general hypothesis that individual species of keystone benthic predators do not occur in the littoral zone of freshwater lentic environments with soft bottoms. We suspect that many of the environmental conditions characteristic of soft-bottom, lentic systems that may have inhibited development of keystone predators are also applicable to some soft-bottom lotic environments and even to some softbottom marine or estuarine systems. If keystone predators are found in some lentic soft-bottom environments, it would be instructive to note which of the following arguments supporting our general hypothesis is invalid and to distinguish the biotic or abiotic characteristics of that system which have promoted evolution or maintenance of a keystone predator.

A keystone species in lentic, soft-bottom environments would, by definition, be capable of disproportionately affecting patterns of prey species occurrence, distribution, and density by preventing monopolization of the major environmental requisites by one prey species (Paine 1966). Disproportionate dominance by one predator and monopolization by one prey species in the littoral zone of lentic systems are unlikely, in our opinion. The following four arguments supporting this premise and our general hypothesis were formed on the basis of personal observations and general literature evidence rather than on direct quantitative data. Direct evidence based on pertinent comparative studies of marine, estuarine and freshwater communities is presently unavailable.

First, environmental heterogeneity should reduce predator efficiency relative to that found in rocky intertidal systems where keystone predation may be present. Although low in heterogeneity, soft-bottom environments provide more refuges in three-dimensional space than afforded by the generally two-dimensional space of rocky intertidal zones. Attached macrophytes add both heterogeneity and refuges to soft-bottom systems.

Second, relative food web complexity should reduce the community importance of an individual predator species. Food web complexity is associated with lower relative abundance of individual predator species. The greater complexity reduces the ability of one predator taxon to prevent monopolization of resources by one dominant prey. Reduced relative abundance of individual predator and prey species also lowers the probability that a potentially dominant prey would be preferentially or exclusively consumed by a keystone species (which may be necessary to prevent monopolization [Paine 1966]).

Third, the apparent relatively greater resource partitioning of space and food in the freshwater littoral zone hinders monopolization of rate-limiting environmental resources by a single dominant prey species. Dominant prey species in rocky intertidal zones are filter-feeding occupants of primary substratum and may be restricted to only a few species (Paine 1966, $1969 a, b$, Dayton 1971). Greater food web and habitat complexities in freshwater littoral zones provide additional niche axes for both competition and coexistence, thus increasing the difficulty for one prey species to dominate the community. Monospecific patches of benthic macroinvertebrates are rarely found in unpolluted freshwater lentic environments (J. H. Thorp, personal observation).

Fourth, the effects of predation may not be extensive enough in time or area to provide sufficient resource space (and thus food) for exploitation by fugitive species. In some rocky intertidal systems starfish and other predators or herbivores increase species diversity and regulate the community by creating open patches for exploitation by motile larvae of less dominant species such as sessile adult barnacles (Dayton 1971). In freshwater soft-bottom systems, however, open patches are probably less frequently created. When they are available, lateral colonization from the highly motile organisms in the contiguous substrata should rapidly deplete freed resources.

If our hypothesis is generally true for soft-bottom littoral systems, then two questions arise. First, what conditions would have to be present to promote the development or maintenance of a keystone species in these environments? And second, what is the importance of nonkeystone predation in these systems?

If a prey were a "foundation species" (Dayton 1972), then a carnivore or an herbivore that could control that prey population would be a keystone species for the benthic community. Foundation species (Day- 
ton 1972) are ". . . disproportionately important to the continued maintenance of the existent community structure. These foundation species usually include those species actually contributing most of the spatial structure of the community, the competitive dominants, and the disturbers preventing their domination." If an organism, such as an omnivorous, freshwater crayfish, were to reduce significantly the plant species that was the major biotic structural component of a pond, then the benthic macroinvertebrate community would be severely disturbed by alteration of the energy flow and habitat complexity of the system. In this situation the crayfish could be considered an indirect keystone species for the benthic community.

In addition to interactions involving foundation species, keystone predators may prove to be important in aquatic communities with low diversity (species richness). For instance, in physically demanding habitats such as hot springs or desert pools, reduction or elimination by a predator of a few prey species might have, in some cases, a relatively dramatic effect on the entire community.

Although we found no evidence of community regulation by the guild of vertebrate predators in Par Pond, an assemblage of predators might be more effective regulators in some systems. Predation-induced diversity ". . . could arise either from the presence of a variety of subwebs of equivalent rank, or from domination by a major one." (Paine 1966). A guild of predators (particularly invertebrates) with different feeding strategies might more effectively harvest prey than a single predator species in a heterogeneous environment. Predator guilds could perhaps regulate density of total macroinvertebrates but probably would not affect prey resource monopolization (and thus species diversity) unless selective predation occurred.

\section{ACKNOWLEDGMENTS}

We are most grateful to Susan Wineriter for her extensive efforts in constructing predator exclusion cages and in the initial experimental sampling. During the dead of winter, Dr. Maureen Diggins graciously donated time in collecting field samples for which we are very thankful. The highly competent help of Jean Coleman and Peggy Langford in drafting figures, and of Sheri Belew and Tonya Willingham in typing the manuscript is appreciated. The aid of Marian Cothran in collating some of the data is acknowledged. Dr. John Pinder's advice in the initial statistical design and final analysis is appreciated. Discussions with Drs. Art Benke, Alan Covich and Roy Stein were quite helpful although the ideas expressed in the final manuscript do not necessarily reflect their viewpoints. Reviews of an earlier manuscript by Drs. Steve Bartell, Arthur Benke, Alan Covich, Barbara Peckarsky and an anonymous reviewer improved the final draft of this paper.

Research support came from contract DE-AC09-76SR00819 between the University of Georgia and the United States Department of Energy, and through an interagency agreement (EPA 79-D-X0533) between the United States Environmental Protection Agency and the Department of Energy.

\section{Literature Cited}

Ball, B. C., and D. W. Hayne. 1952. Effects of the removal of the fish population on the fish-food organisms of a lake. Ecology 33:41-48.
Benke, A. C. 1976. Dragonfly production and prey turnover. Ecology 57:915-927.

- 1978. Interactions among coexisting predators-a field experiment with dragonfly larvae. Journal of Animal Ecology 47:335-350.

Bennett, D. H., and J. W. Gibbons. 1972. Food of largemouth bass (Micropterus salmoides) from a South Carolina reservoir receiving heated effluent. Transactions of the American Fisheries Society 101:650-654.

Clugston, J. P. 1973. The effects of heated effluents from a nuclear reactor on species diversity, abundance, reproduction, and movement of fish. Dissertation. University of Georgia, Athens, Georgia, USA.

Cochran, W. G. 1963. Sampling techniques. Second edition. Wiley, New York, New York, USA.

Connell, J. H. 1970. A predator-prey system in the marine intertidal region. I. Balanus glandula and several predatory species of Thais. Ecological Monographs 40:49-78.

Dayton, P. K. 1971. Competition, disturbance, and community organization: the provision and subsequent utilization of space in a rocky intertidal community. Ecological Monographs 41:351-389.

- 1972. Toward an understanding of community resilience and the potential effects of enrichments to the benthos at McMurdo Sound, Antarctica. Pages 81-95 in B. C. Parker, editor. Proceedings of the Colloquium on Conservation Problems in Antarctica. Allen Press, Lawrence, Kansas, USA.

Dodson, S. I. 1970. Complementary feeding niches sustained by size-selective predation. Limnology and Oceanography 15:131-137.

Eisenberg, R. M. 1966. The regulation of density in a natural population of the pond snail, Lymnaea elodes. Ecology 47:889-905.

Fisher, R. A. 1932. Statistical methods for research workers. Fourth edition. Oliver and Boyd, Edinburgh, Scotland.

Hall, D. J., W. E. Cooper, and E. E. Werner. 1970. An experimental approach to the production dynamics and structure of freshwater communities. Limnology and Oceanography 15:839-928.

Hayne, D. W., and R. C. Ball. 1956. Benthic productivity as influenced by fish predation. Limnology and Oceanography $1: 162-175$.

Helwig, J. T., and K. A. Council. 1979. Statistical Analysis System user's guide. Statistical Analysis System Institute, Raleigh, North Carolina, USA.

Kajak, Z. 1963. The effect of experimentally induced variations in the abundance of Tendipes plumosus L. larvae on intraspecific relations. Ekologia Polska Seria A 11:355367.

Kirk, R. E. 1968. Experimental design: procedures for the behavioral sciences. Brooks and Cole, Belmont, California, USA.

Menge, B. A. 1976. Organization of the New England rocky intertidal community: role of predation, competition, and community heterogeneity. Ecological Monographs 46:355393.

Menge, B. A., and J. P. Sutherland. 1976. Species diversity gradients: synthesis of the roles of predation, competition, and temporal heterogeneity. American Naturalist 110:351369.

Merritt, R. W., and K. W. Cummins. 1978. An introduction to the aquatic insects of North America. Kendall/Hunt, Dubuque, Iowa, USA.

Paine, R. T. 1966. Food web complexity and species diversity. American Naturalist 100:65-75.

-1969a. A note on trophic complexity and community stability. American Naturalist 103:91-93.

- 1969h. The Pisaster-Tegula interaction: prey patches, predator food preference, and intertidal community structure. Ecology 50:950-961.

Parmenter, R. R. 1980. Effects of food availability and 
water temperature on the feeding ecology of pond sliders (Chrysemys s. scripta Schoepff). Copeia 3:503-514.

Peckarsky, B. L. 1979. Biological interactions as determinants of distributions of benthic invertebrates within the substrate of stony streams. Limnology and Oceanography 24:59-68.

Stewart, K. W. 1975. An improved elutriator for separating stream insects from stony substrates. Transactions of the American Fisheries Society 1975:821-823.

Sutherland, J. P., and R. Karlson. 1977. Development and stability of the fouling community at Beaufort, North Carolina. Ecological Monographs 47:425-446.
Virnstein, R. W. 1977. The importance of predation by crabs and fishes on benthic infauna in Chesapeake Bay. Ecology 58:1199-1217.

1979. Predation on estuarine infauna: response patterns of component species. Estuaries 2:69-86.

Woodin, S. A. 1974. Polychaete abundance patterns in a marine soft-sediment environment: the importance of biological interactions. Ecological Monographs 44:171-187.

. 1978. Refuges, disturbance, and community structure: a marine soft-bottom example. Ecology 59:274-284. 